\title{
Optical Properties and van der Waals-London Dispersion Interactions of Polystyrene Determined by Vacuum Ultraviolet Spectroscopy and Spectroscopic Ellipsometry
}

\author{
Roger H. French, ${ }^{\text {A, B,C Karen I. Winey, }}{ }^{\mathrm{B}}$ Min K. Yang, ${ }^{\mathrm{A}}$ and Weiming Qiu ${ }^{\mathrm{A}}$ \\ ${ }^{A}$ DuPont Central Research, E356-384 Experimental Station, Wilmington, DE 19880, USA. \\ ${ }^{B}$ Department of Materials Science and Engineering, University of Pennsylvania, \\ Philadelphia, PA 19104, USA. \\ ${ }^{\mathrm{C}}$ Corresponding author. Email: roger.h.french@usa.dupont.com
}

\begin{abstract}
The interband optical properties of polystyrene in the vacuum ultraviolet (VUV) region have been investigated using combined spectroscopic ellipsometry and VUV spectroscopy. Over the range 1.5-32 eV, the optical properties exhibit electronic transitions we assign to three groupings, $E_{1}, E_{2}$, and $E_{3}$, corresponding to a hierarchy of interband transitions of aromatic $\left(\pi \rightarrow \pi^{*}\right)$, non-bonding $\left(n \rightarrow \pi^{*}, n \rightarrow \sigma^{*}\right)$, and saturated $\left(\sigma \rightarrow \sigma^{*}\right)$ orbitals. In polystyrene there are strong features in the interband transitions arising from the side-chain $\pi$ bonding of the aromatic ring consisting of a shoulder at $5.8 \mathrm{eV}\left(\mathrm{E}_{1}^{\prime}\right)$ and a peak at $6.3 \mathrm{eV}\left(\mathrm{E}_{1}\right)$, and from the $\sigma$ bonding of the $\mathrm{C}-\mathrm{C}$ backbone at $12 \mathrm{eV}\left(\mathrm{E}_{3}^{\prime}\right)$ and $17.1 \mathrm{eV}$ $\left(E_{3}\right)$. These $E_{3}$ transitions have characteristic critical point line shapes associated with one-dimensionally delocalized electron states in the polymer backbone. A small shoulder at $9.9 \mathrm{eV}\left(\mathrm{E}_{2}\right)$ is associated with excitations possibly from residual monomer or impurities. Knowledge of the valence electronic excitations of a material provides the necessary optical properties to calculate the van der Waals-London dispersion interactions using Lifshitz quantum electrodynamics theory and full spectral optical properties. Hamaker constants and the van der Waals-London dispersion component of the surface free energy for polystyrene were determined. These Lifshitz results were compared to the total surface free energy of polystyrene, polarity, and dispersive component of the surface free energy as determined from contact angle measurements with two liquids, and with literature values. The Lifshitz approach, using full spectral Hamaker constants, is a more direct determination of the van der Waals-London dispersion component of the surface free energy of polystyrene than other methods.
\end{abstract}

Manuscript received: 28 June 2006.

Final version: 11 February 2007.

\section{Introduction}

Given the broad range of technological applications and scientific studies of polymers, it is surprising that the electronic structure and optical properties of polymers beyond the simple ultraviolet (UV) and visible (vis) spectral regions have not been extensively studied to date. We determined the electronic structure and complex optical properties of polystyrene (PS) over the energy range spanning the valence electronic excitations, and used these optical properties with Lifshitz theory to determine Hamaker constants of the van der Waals-London dispersion (vdW-Ld) interactions.

The vdW-Ld dispersion interaction, the main component of the van der Waals forces, ${ }^{[1]}$ is a universal, long-range interaction present for all materials that arises directly from the electronic structure and optical properties of materials. ${ }^{[2]}$ Once the full spectral optical properties and electronic structure of PS have been determined, the London dispersion interaction and full spectral Hamaker constant ${ }^{[3]}$ can be determined using the Lifshitz method. ${ }^{[4,5]}$ In the simple example of two pieces of material 1 separated by an interlayer material, material 2, the Hamaker constant, $A_{121}^{N R}$, determines the magnitude of the vdW-Ld force ( $\left.F_{\mathrm{vdW}-\mathrm{Ld}}\right)$ between the two grains, as defined by Eqn 1. The intervening material shields the vdW-Ld attraction of the two materials. The Hamaker constant is large for a vacuum interlayer, and zero if the interlayer material 2 is identical to the two other materials 1 and 3 . The intimate relationship between the electronic structure and optical properties, ${ }^{[6]}$ and this universal vdW-Ld interaction has attracted increased interest in the fields of materials science, ${ }^{[7-9]}$ physics, chemistry, and biology. ${ }^{[10]}$ A general characteristic is the role of $\mathrm{vdW}-\mathrm{Ld}$ in wetting ${ }^{[11]}$ and adhesion, and thus, a detailed knowledge of the optical properties and dispersion interaction in PS is of increased interest. $^{[12]}$

$$
A_{121}^{N R}=-6 \pi \mathrm{L}^{3} F_{\mathrm{vdW}-\mathrm{Ld}}
$$

These vdW-Ld interactions are quantum electrodynamical in origin, are defined by the fundamental optical properties and electronic structure of materials, and give rise to the vdW-Ld component of the surface free energy (SFE) of a material. They are often the main component of the SFE of a polymer such as PS. The vdW-Ld (dispersive) and non-dispersive (or polar) components of the SFE of a polymer are usually determined from pendant drop or sessile drop contact angle measurements. We use the Fowkes method ${ }^{[13,14]}$ with two fluids to determine the SFE, and the vdW-Ld and polar components of the SFE of 
PS for comparison to that determined from the [PS | vacuum | PS] Hamaker constant of the vdW-Ld interaction.

\section{Electronic Structure and Optical Properties of Polymers}

There are prior reports on the electronic excitations and optical transitions of various polymers over limited energy ranges such as poly(methyl methacrylate) (PMMA), ${ }^{[15,16]}$ bisphenol A polycarbonate (PC), ${ }^{[17]}$ low-density polyethylene (LDPE), ${ }^{[18]}$ and from 250 to $170 \mathrm{~nm}$ on polyethylene (PE), polytetrafluoroethylene (PTFE), styrene allyl alcohol (SAA), and other polymers. ${ }^{[19]}$ We previously studied seven different poly(dialkylsilanes) $)^{[20,21]}$ using quantitative analysis of vacuum ultraviolet (VUV) reflectance measurements to determine the interband transition strength $\left(J_{\mathrm{cv}}\right)$ so as to develop a hierarchy of the optical excitations in these silicon backbone polymers. For poly(di- $n$-hexylsilane), we used critical point analysis ${ }^{[22]}$ and band structure calculations ${ }^{[23]}$ under the local density approximation to study the transitions in greater detail.

Ritsko $^{[24]}$ reported the electronic excitations in polymers including PS, PMMA, and PC (Lexan), and broadly categorized the excitations into three groups: (i) $\pi \rightarrow \pi^{*}$ transitions of phenyl rings; (ii) carbonyl ( $\left.\mathrm{n} \rightarrow \pi^{*}, \mathrm{n} \rightarrow \sigma^{*}\right)$ transitions; and (iii) $\sigma \rightarrow \sigma^{*}$ transitions. He also reported a peak in the energy loss function of PS at $7 \mathrm{eV}$. Nakai et al. ${ }^{[25]}$ measured the optical properties and reported the energy loss function and optical sum rules for PS and P(SMMA) (poly(styrene-methyl methacrylate) random copolymer) copolymers. They found the main peak in the energy loss function at $6.7 \mathrm{eV}$ and assigned it to ${ }^{1} \mathrm{~A}_{1 \mathrm{~g}} \rightarrow{ }^{1} \mathrm{E}_{1 \mathrm{u}}$ transitions of phenyl (benzene) ring $\pi$ electron transitions. The f-sum rule for the effective number of electrons per monomeric unit through the $6.7 \mathrm{eV}$ peak gives 0.3 instead of the expected six electrons. Rocco et al. ${ }^{[26]}$ published the measured electronic excitations and optical transitions of styrene (S) and MMA (methyl methacrylate) monomers. For styrene monomers they found electronic transition energies at 5.3, 7.7, 10.3, 11.8, 13.7, and $17.1 \mathrm{eV}$.

\section{Surface Free Energy Dispersive and Non-Dispersive Components}

The surface and interface energies of materials are related to unsatisfied chemical bonds, dispersion effects arising from the optical contrast, and to polar effects. These thermodynamic energies help determine the wetting of solids by liquids. The thermodynamics of wetting has spanned from the work of Taylor and Hauksbee, ${ }^{[27]}$ Young, ${ }^{[28]}$ Gibbs, ${ }^{[29,30]}$ and van der Waals ${ }^{[31]}$ to the critical wetting theory of $\mathrm{Cahn}^{[32,33]}$ and the development of the effective interface potential approach. ${ }^{[34]}$ Surface and interface energies, and the contact angle at the triple point between the solid, liquid, and gas phases as shown in Fig. 1 has been an active topic in science for centuries. Today, the study has progressed to the detailed variations of three-dimensional droplets and their contact lines. ${ }^{[35]}$ The Young equation, Eqn 2, relates the contact angle to the surface and interface energies of the solid and liquid, through the use of a force balance at the interface. The closely related Young-Dupre equation, Eqn 3, then defines the work of adhesion as the difference between the free surface energies of the solid, and the liquid and the solid-liquid interface energy:

$$
\begin{gathered}
\gamma_{\text {liq. }} \cos \theta=\gamma_{\text {sol. }}-\gamma_{\text {sol.-liq. }} \\
W_{a d}=\gamma_{\text {sol. }}+\gamma_{\text {liq. }}-\gamma_{\text {sol.-liq. }}
\end{gathered}
$$

The total surface free energy (SFE, $\gamma$ ), can be subdivided into various contributions, with the most common as the separation

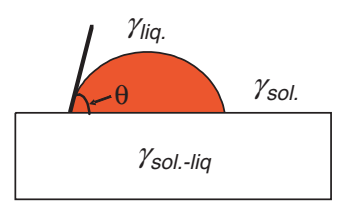

Fig. 1. Schematic drawing of a liquid droplet on a solid substrate. $\gamma_{\text {sol. }}$ is the solid surface energy, $\gamma_{\text {liq }}$ is the liquid surface energy, and $\gamma_{\text {sol.-liq. }}$ is the solid-liquid interface energy.

into dispersive $\left(\gamma^{\text {Disp. }}\right)$ and polar $\left(\gamma^{\text {Polar }}\right)$ components, as shown in Eqn 4. ${ }^{[36]}$ The dispersive component of the surface free energy is non-polar since it arises from transient induced fluctuations of the electron bonds of materials, as described by the vdW-Ld dispersion interaction. The polarity $\left(x^{P}\right)$ can then be defined by Eqn 5. The polar component has been further subdivided, for example into acid (electron acceptor) $\left(\gamma^{+}\right)$and base (electron donor) $\left(\gamma^{-}\right)$components $^{[37]}$ (Eqn 6), or alternatively into dipolar $\left(\gamma^{\text {Dipolar }}\right)$ and hydrogen-bonding $\left(\gamma^{H}\right)$ components (Eqn 7):

$$
\begin{gathered}
\gamma=\gamma^{\text {Disp. }}+\gamma^{\text {Polar }} \\
x^{P}=\gamma^{\text {Polar }} / \gamma \\
\gamma^{\text {Polar }}=2 \sqrt{\gamma^{+} \gamma^{-}} \\
\gamma^{\text {Polar }}=\gamma^{\text {Dipolar }}+\gamma^{H}
\end{gathered}
$$

Many different methods have been used to determine the total SFE of polymers, including pendant and sessile PS drop approaches, PS sessile drop spreading experiments, and sessile drop experiments of liquids on PS substrates. Other work using contact angles of fluids on substrates report the SFE of PTFE, ${ }^{[38]}$ and the SFE of dissolving hydrocarbon solids. ${ }^{[39]}$ PS results are summarized in Table 1. The Polymer Handbook ${ }^{[36]}$ reports an SFE of $40.7 \mathrm{~mJ} \mathrm{~m}^{-2}$ at $20^{\circ} \mathrm{C}$ for high molecular weight PS ( $M W 44000)$. From a reported polarity $x^{P}$ of 0.168 , its dispersive surface energy is $33.9 \mathrm{~mJ} \mathrm{~m}^{-2}$ and polar surface energy is $6.8 \mathrm{~mJ} \mathrm{~m}^{-2}$. For lower molecular weight ( $\left.M W 9300\right)$, the surface energy of PS at $20^{\circ} \mathrm{C}$ is $39.4 \mathrm{~mJ} \mathrm{~m}^{-2}$. The finding that the SFE decreases linearly with molecular weight has also been shown for small molecule alkanes. ${ }^{[40]}$ From pendant drop measurements at $100-180^{\circ} \mathrm{C}, \mathrm{Wu}^{[41]}$ found the SFE of PS to be $32.1 \mathrm{~mJ} \mathrm{~m}^{-2}$ at $140^{\circ} \mathrm{C}$. Linear extrapolation gives the SFE of PS to be $40.7 \mathrm{~mJ} \mathrm{~m}^{-2}$ at $20^{\circ} \mathrm{C}$ from pendant drop, or $37.5 \mathrm{~mJ} \mathrm{~m}^{-2}$ from sessile drop measurements. Measuring the interfacial energies among various polymers including polyethylene (a non-polar polymer), the dispersive component of the surface energy of PS at $20^{\circ} \mathrm{C}$ is $32.5 \mathrm{~mJ} \mathrm{~m}^{-2}$, suggesting that PS has polarity $x^{P}$ of 0.20 . From pendant and sessile drop measurements from 90 to $175^{\circ} \mathrm{C},{ }^{[42]}$ and the rate of spreading of polymer melts on solid surfaces, Lau et al. ${ }^{[4,44]}$ found the SFE for PS with $M W 40000$ at $140^{\circ} \mathrm{C}$ to be $33 \mathrm{~mJ} \mathrm{~cm}^{-2}$ and an extrapolated value of $44 \mathrm{~mJ} \mathrm{~cm}^{-2}$ at $20^{\circ} \mathrm{C}$. They also found a linear decrease in SFE with temperature and molecular weight.

Dagastine et al. constructed the optical spectra for water ${ }^{[45]}$ and polystyrene ${ }^{[46]}$ from damped oscillator fits to experimental data. They then use these spectra and Lifshitz theory to calculate the Hamaker constant of [PS | water | PS] to be $8.9 \mathrm{zJ}$ $\left(1 \mathrm{zJ}=10^{-21} \mathrm{~J}\right.$ and $4.1 \mathrm{zJ}=1 \mathrm{kT}$; Hamaker constants are sometimes reported in $\mathrm{kT}$ units, where $\mathrm{T}$ is not a variable but room temperature). Using an optical spectrum of polystyrene constructed in a similar manner by Parsegian and Weiss ${ }^{[47]}$ with Dagastine 

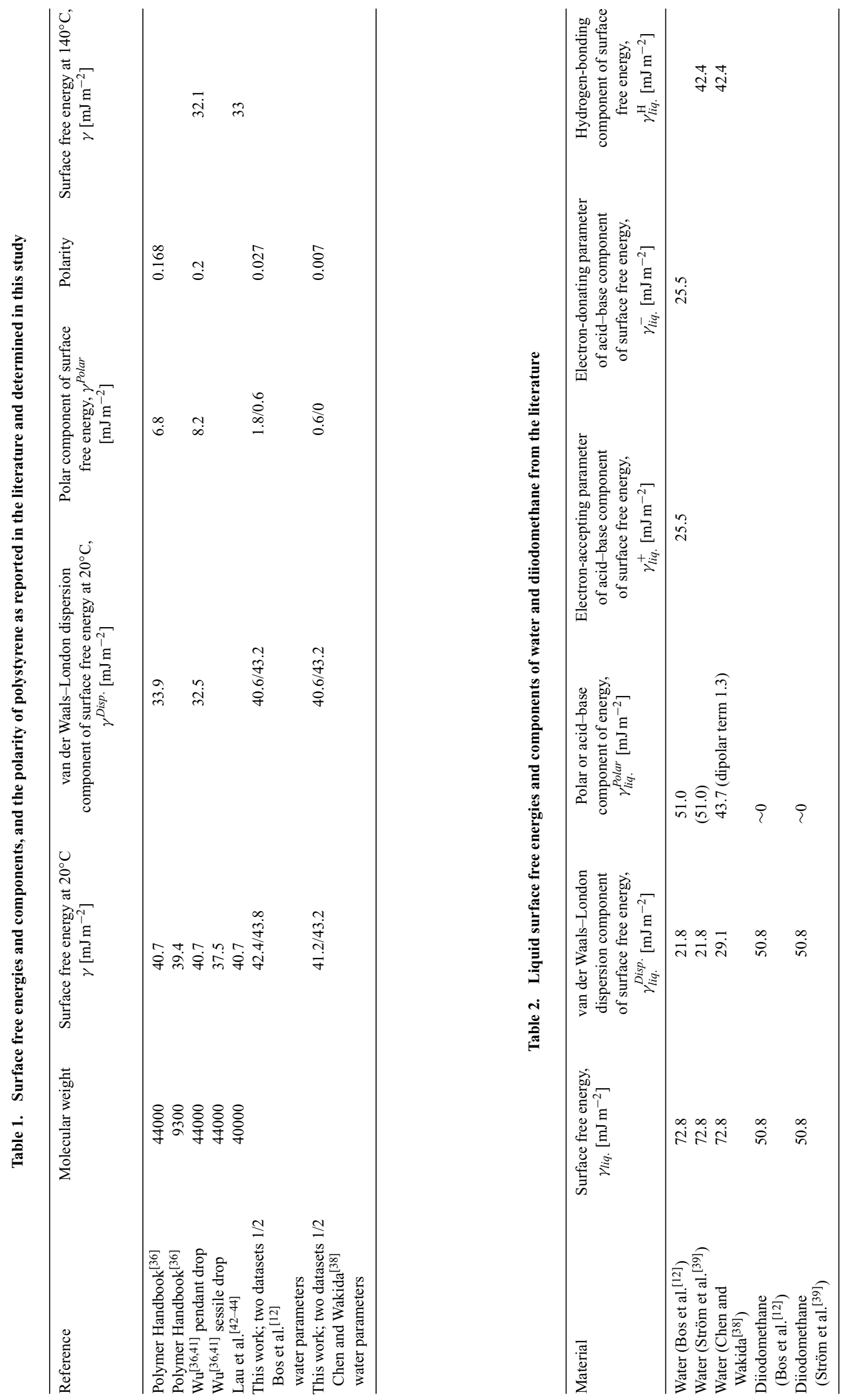
et al.'s ${ }^{[45]}$ water spectrum, they find a [PS | water | PS] Hamaker constant of $9.63 \mathrm{zJ}$.

The results in Tables 1 and 2 show that the SFE, polarity, and dispersive component of the SFE of PS are not well established, since these values are determined from various methods, and vary with temperature, molecular weight, and surface condition of samples. In this work, we attempt to determine the dispersive component of the SFE directly from the electronic structure and optical properties.

\section{Surface Free Energy Determination Using Two Fluids and the Fowkes Method}

Another common experimental method to determine the dispersive and polar components of the SFE of a material is to use drops of two sessile liquids, typically water and diiodomethane, measure the contact angles on the solid, then calculate using the Fowkes method. ${ }^{[13,14]}$ We have done that here, to provide our own results on the SFE of PS. It is quickly shown that the dispersive and polar components of the SFE of liquids are as ill defined in the literature as are polymer surfaces, directly limiting the ability of the Fowkes method to accurately determine these components of the SFE of a polymer.

Bos et al., ${ }^{[12]}$ in a review of work on bacterial adhesion, report on surface free energies and the polar and dispersive contributions to the SFE for water and diiodomethane, ${ }^{[48]}$ which are the fluids used here with the Fowkes method. They also discuss polar, dispersive, and acid-base contributions to interfacial interaction energies and interactions. In discussing the vdW-Ld dispersion interactions, they also reported Hamaker constants for [PS $\mid$ water $\mid$ PS] systems. Citing an earlier thesis, ${ }^{[49]}$ they report that, as determined from contact angle measurements, the Hamaker constant for the vdW-Ld interaction for [PS | water | PS] is $5 \mathrm{zJ}$. They also found other Hamaker constant determinations for this system to be in the range 3.52-5.32 zJ. The non-polar nature of diiodomethane is agreed upon by most authors (even though some attribute a small polar component of the SFE of diiodomethane), but the polarity $x^{P}$ of water is less well agreed upon. We summarize liquid SFE values $\left(\gamma_{\text {liq. }}\right)$ for these liquids in Table 2.

\section{Present Work}

Here we report VUV reflectance measurements from 4 to $32 \mathrm{eV}$ (310 to $41 \mathrm{~nm}$ ), with spectroscopic ellipsometry measurements from 1 to $8.25 \mathrm{eV}$ (1240 to $150 \mathrm{~nm}$ ). To quantitatively determine the electronic structure of PS we have used Kramers-Kronig analysis $^{[50,51]}$ to determine the complex optical properties of PS over the complete energy range, encompassing the valence electronic structure. These results are essential information to calculate the full spectral Hamaker constants for vdW-Ld dispersion interactions for configurations including PS. We calculate the vdW-Ld dispersion surface free energy from the electronic structure and optical properties determined, and compare these values with the SFE and its polar and dispersive components as determined from the application of the Fowkes method to contact angle measurements of two fluids.

\section{Experimental}

\section{Sample Preparation}

Amorphous samples of PS, $-\left[\mathrm{CH}_{2} \mathrm{CH}\left(\mathrm{C}_{6} \mathrm{H}_{5}\right)\right]-$, were used for the VUV and ellipsometry investigations and contact angle measurement. PS-677 has a high molecular weight ( $M W$ 250000) with a glass transition temperature, $T_{g}$, of $100^{\circ} \mathrm{C}$, which was pressed in a $\mathrm{KBr}$ pellet press at $140^{\circ} \mathrm{C}$ against the optically smooth surface of a sapphire window. PS-568 was produced by Althor Products ${ }^{[52]}$ using Chevron Phillips ${ }^{[53]}$ High Heat Crystal PS grade MC3100, which has a specific gravity of $1.03 \mathrm{~g} \mathrm{~cm}^{-3}$, a typical molecular weight $>250000$, and a residual styrene monomer concentration $<0.1 \mathrm{wt} \%$. Both PS samples are atactic and thereby have amorphous structure.

\section{Spectroscopic Ellipsometry}

Spectroscopic ellipsometry was performed with the VUV-Vase instrument, ${ }^{[54]}$ which has a range $0.69-8.55 \mathrm{eV}(1800-145 \mathrm{~nm})$, and uses $\mathrm{MgF}_{2}$ polarizers and analyzers rather than the more common calcite optics. The instrument has an $\mathrm{MgF}_{2}$ autoretarder and is fully nitrogen purged. The spot diameter of the light source on the surface of the sample is $2 \mathrm{~mm}$. Ellipsometric measurements were conducted using light incident at angles of 60,70 , and $80^{\circ}$ relative to normal on the front surface of the sample, the back of which was roughened with coarse polishing paper. The instrument measures the ellipsometric parameters $\Psi$ and $\Delta$, which are defined by Eqn 8 :

$$
\tan (\Psi) e^{i \Delta}=\frac{R_{P}}{R_{S}}
$$

where $R_{P} / R_{S}$ is the complex ratio of the p- and s-polarized components of the reflected amplitudes. These parameters are analyzed using the Fresnel equations ${ }^{[55]}$ in a computer-based modelling technique including a surface roughness layer to directly determine the optical constants.

\section{VUV Spectroscopy}

VUV spectroscopy has become an established technique for electronic structure studies of materials. ${ }^{[56-60]}$ It has the advantage of covering the complete energy range of the valence interband transitions and is not plagued by the sample charging that attends photoelectron spectroscopy on insulating samples. The VUV spectrophotometer includes a laser plasma light source, a monochromator, filters, and detectors. ${ }^{[61]}$ The light source is not polarized, and the incident angle of the light on the sample is near normal. Instrument details have been discussed previously. ${ }^{[62]}$ The energy range of the instrument is $1.7-44 \mathrm{eV}(700-28 \mathrm{~nm})$, which allows extension beyond the air cut-off of $6 \mathrm{eV}$ and the window cut-off of $10 \mathrm{eV}$. The resolution of the instrument is $0.2-0.6 \mathrm{~nm}$, which corresponds to $16 \mathrm{meV}$ resolution at $10 \mathrm{eV}$ and $200 \mathrm{meV}$ resolution at $35 \mathrm{eV}$.

\section{Contact Angle Measurements}

The sessile drop method was adopted for the measurement. The method uses a drop lying on the PS surface for contact angle measurement. The needle size was $0.5 \mathrm{~mm}$ in diameter. A volume dosing mode was used and the volume was $0.5 \mu \mathrm{L}$. The dose rate was approximately $800 \mu \mathrm{L} \mathrm{min}^{-1}$.

The instrument used for contact angle measurement was a DSA-100, manufactured by KRUSS. The liquid diiodomethane was A15457 99\% from Alfa Aesar. For the calculation of the surface energy for diiodomethane, SFE was $50.8 \mathrm{~mJ} \mathrm{~m}^{-2}$, dispersive component $50.8 \mathrm{~mJ} \mathrm{~m}^{-2}$; therefore, the polar part was $0 \mathrm{~mJ} \mathrm{~m}^{-2}$ and the mean contact angle of ten measurements on PS-568 polystyrene (from Althor) for dataset 1 was $37.8^{\circ}$ and for dataset 2 was $32.3^{\circ}$. For the calculation of the surface free energy for water using Bos et al. ${ }^{[12]} /$ Chen and Wakida ${ }^{[38]}$ parameters for 
water, the liquid surface free energy was $72.8 / 72.8 \mathrm{~mJ} \mathrm{~m}^{-2}$, dispersive part $21.8 / 29.1 \mathrm{~mJ} \mathrm{~m}^{-2}$, the polar part $51.0 / 43.7 \mathrm{~mJ} \mathrm{~m}^{-2}$, and the mean contact angle of ten measurements on PS for dataset 1 was $85.2^{\circ}$ and for dataset 2 was $90.2^{\circ}$

\section{Results}

\section{Analysis of Ellipsometry Data}

Transmission spectra for both samples of PS within the VUV range are shown in Fig. 2. We use both ellipsometric and UVvis transmission data taken on the same sample to find a model describing the optical behaviour of the PS. ${ }^{[51]}$ Using transmission data and ellipsometric data in the modelling reduces the effective surface sensitivity of ellipsometry, while increasing the accuracy of the bulk properties determined from the quantitative analysis. The complex index of refraction for both samples of PS within the energy range $0.7-8 \mathrm{eV}$ for this solution is shown in Fig. 3.

\section{Kramers-Kronig Analysis of VUV Reflectance}

The analysis of the spectra was done using electronic structure tools. ${ }^{[63]}$ Accurate results from Kramers-Kronig analysis rely on the accurate determination of the amplitude of the VUV reflectance (Fig. 4), and preparation of low and high energy wings that extend beyond the experimental data range. We prepared the low-energy wing, in the range below the band gap of the material with PS (for energies $<4 \mathrm{eV}$ ), using a two-pole Sellmeier form, and fitting the reflectance with this low-energy wing to the ellipsometric data in a least-squares sense. In this

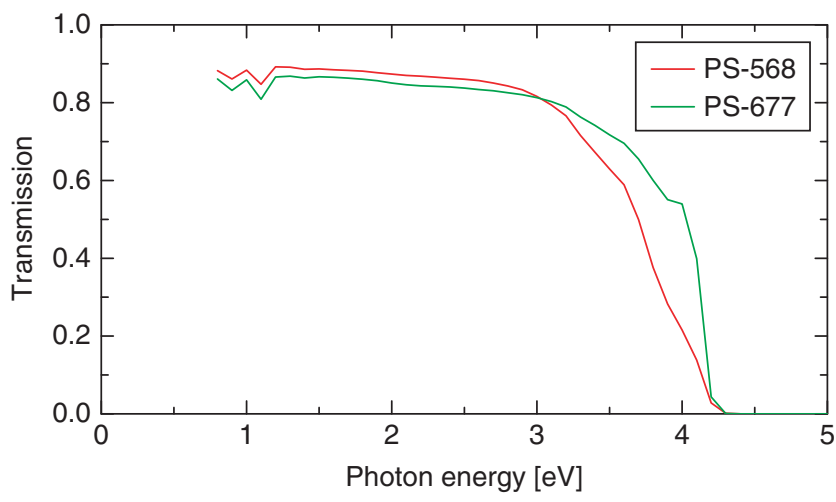

Fig. 2. Transmission of two polystyrene samples.

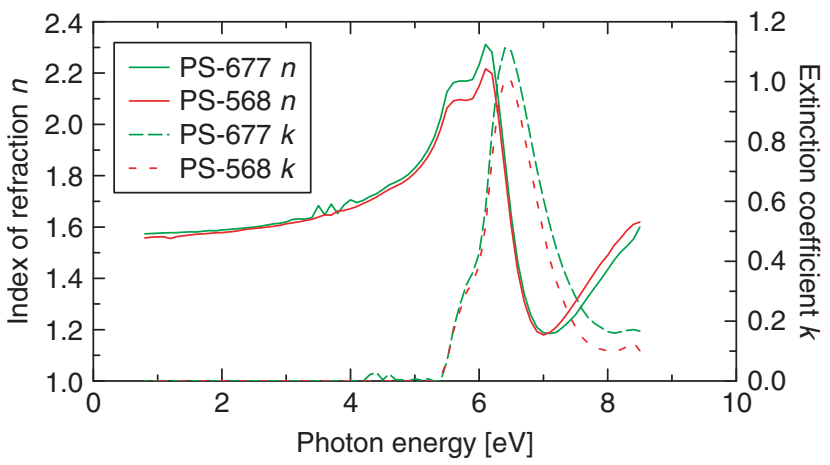

Fig. 3. Complex index of refraction, $\hat{n}=n+i k$, determined for two polystyrene samples. Indices of refraction, $n$ (solid line), extinction coefficients, $k$ (dashed line). manner, we determined more accurately the reflectance amplitude and low-energy wing, which will be used as input in the Kramers-Kronig analysis. We also prepared and fitted a highenergy wing for the reflectance. The methods are detailed in our previous work. ${ }^{[51]}$ Kramers-Kronig analysis was then used to recover the reflected phase of the light. In the case of normal incidence, the complex reflection coefficient is written in terms of the amplitude $\bar{R}$ and a phase shift upon reflection $\theta$, as described by Eqn 9. ${ }^{[64]}$

$$
\tilde{R}=|\bar{R}| e^{-i \theta}=\frac{n-1-i k}{n+1-i k}
$$

The complex indices of refraction $(\hat{n}=n+i k)$ for both samples of PS are then calculated algebraically from Eqn 9 and the results for PS-568 are shown in Fig. 5.

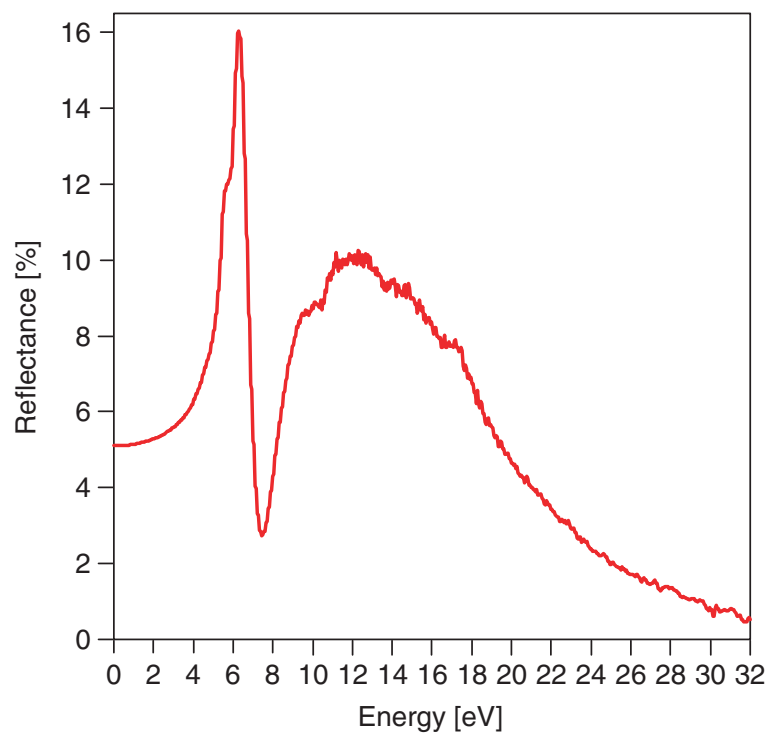

Fig. 4. Reflectance of VUV spectrum measured from polystyrene sample PS-568.

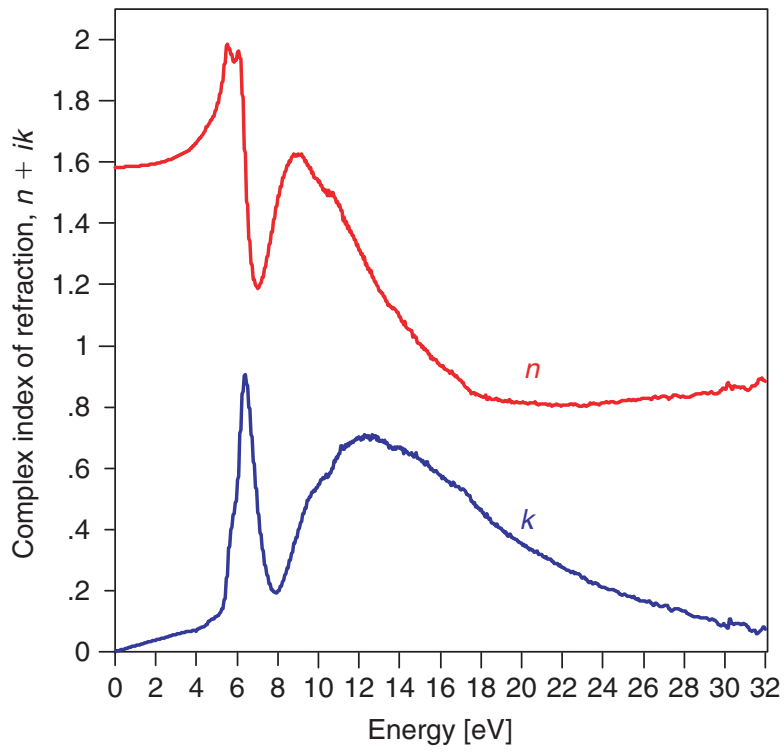

Fig. 5. Complex index of refraction of polystyrene sample PS-568. 
Fundamental absorption edge spectra have been determined by Eqn $10 .{ }^{[64]}$

$$
\alpha=\frac{4 \pi k}{\lambda}
$$

where $\alpha$ is the absorption coefficient, $\lambda$ is the wavelength of the light source and $\mathrm{k}$ is the extinction coefficient. The fundamental absorption spectra for the two samples of PS are shown in Fig. 6 (spectroscopic ellipsometry) and Fig. 7 (VUV spectroscopy).

Once the dielectric function is derived, the complex interband transition strength $J_{c v}$, shown in Fig. 8, and in Fig. 9 on an expanded energy scale, can be calculated by Eqn 11. ${ }^{[2]}$

$$
J_{c v}(E)=J_{c v}^{\prime}+i J_{c v}^{\prime \prime}=\frac{m_{0}^{2}}{e^{2} \hbar^{2}} \frac{E^{2}}{8 \pi^{2}}\left(\varepsilon^{\prime \prime}(E)+i \varepsilon^{\prime}(E)\right),
$$

where $m_{0}$ is the electron mass and $e$ its charge. $J_{c v}^{\prime}$ and $J_{c v}^{\prime \prime}$ correspond to the real and imaginary parts of the complex joint densities of states, respectively. The bulk and surface energy loss function of PS $(E L F=-\operatorname{Im}[1 / \varepsilon(\omega)])$ as defined in Eqns 12 and 13 are shown in Fig. 10.

$$
\text { Bulk } E L F=-\operatorname{Im}\left[\frac{1}{\varepsilon(E)}\right]
$$

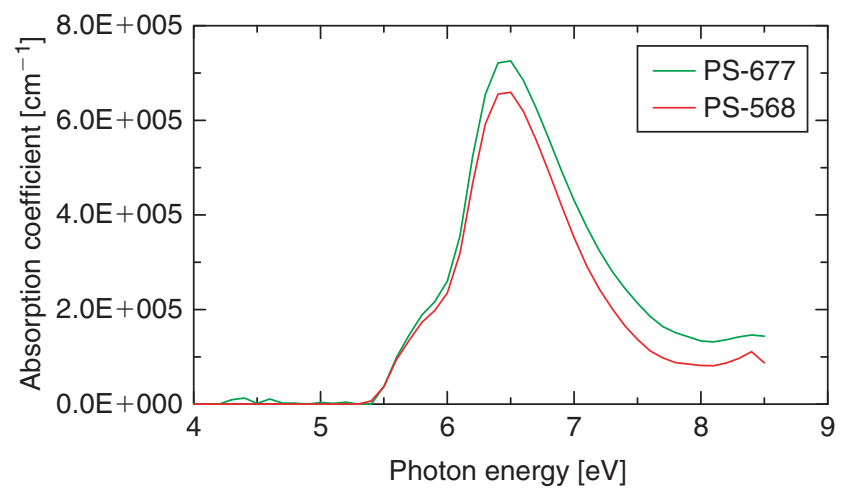

Fig. 6. Fundamental absorption edge of polystyrene within the low energy range for two samples, determined from spectroscopic ellipsometry measurement and subsequent Fresnel analysis.

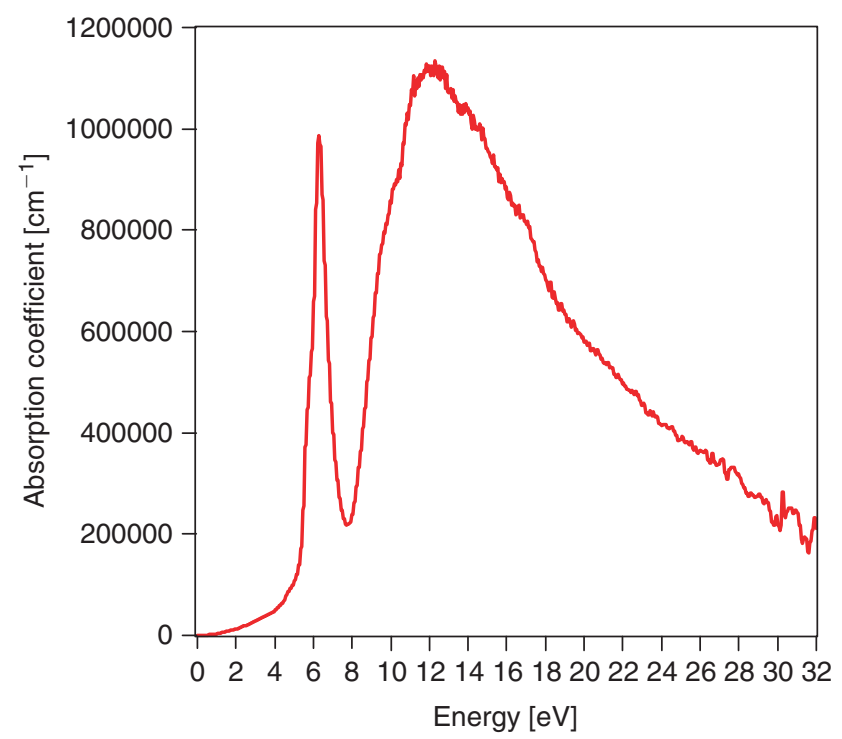

Fig. 7. Fundamental absorption edge of sample PS-568 for the full energy range studied. Absorption coefficient, $\alpha$, is plotted against energy.

$$
\text { Surface } E L F=-\operatorname{Im}\left[\frac{1}{\varepsilon(E)+1}\right]
$$

The effective number of electrons per cubic nanometer, $n_{\text {eff }}$, contributing to interband transitions up to energy $E$ is calculated using the oscillator strength or f-sum rule ${ }^{[65]}$ evaluated for the real part of $J_{c v}\left(J_{c v}^{\prime}\right)$ as shown in Eqn 14, and for the effective number of electrons per atomic formula unit, $n_{\text {eff }-v}$ in Eqn 15:

$$
\begin{gathered}
n_{e f f}(E)=\frac{m_{0}}{2 \pi^{2} \hbar^{2} e^{2}} \int E \varepsilon^{\prime \prime}(E) d E=\frac{4}{m_{0}} \int_{0}^{E} \frac{J_{c v}^{\prime}(E)}{E} d E \\
n_{e f f-v}(E)=\frac{4 \dot{v}_{f}}{m_{0}} \int_{0}^{E} \frac{J_{c v}^{\prime}(E)}{E} d E
\end{gathered}
$$

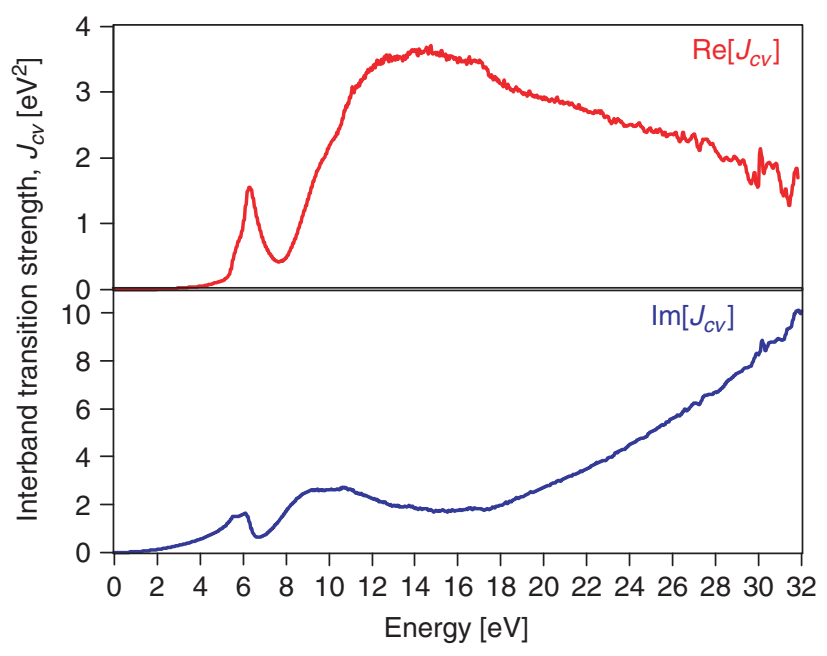

Fig. 8. $\operatorname{Real}\left(\operatorname{Re}\left[J_{c v}\right]\right)$ and imaginary $\left(\operatorname{Im}\left[J_{c v}\right]\right)$ parts of the interband transition strength and of polystyrene sample PS-568 for the full energy range studied, determined from Kramers-Kronig analysis of VUV reflectance data.

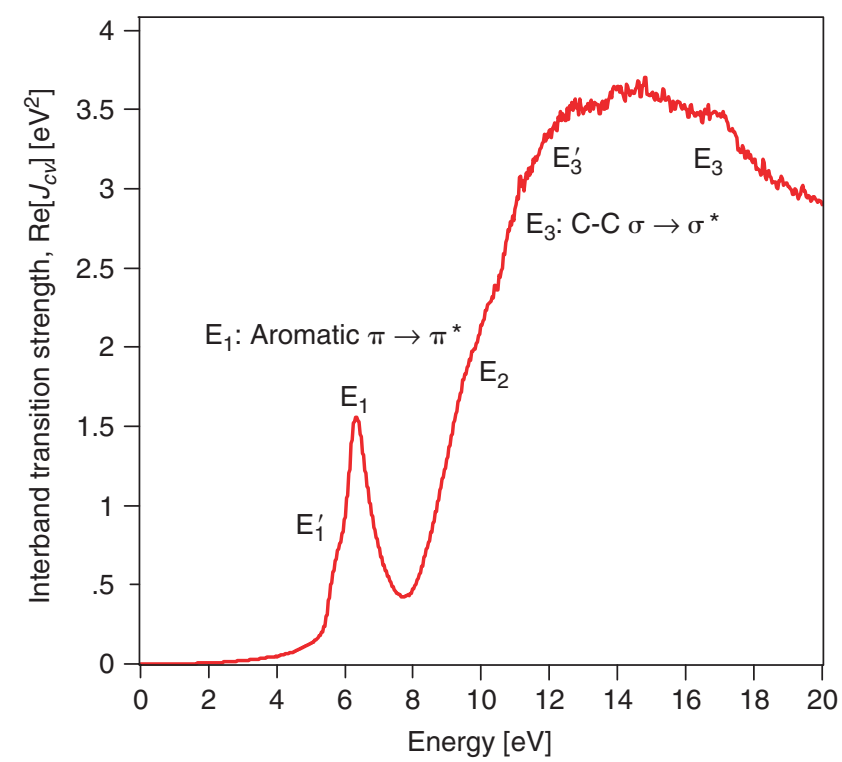

Fig. 9. Real part of the interband transition strength $\left(\operatorname{Re}\left[J_{c v}\right]\right)$ of polystyrene sample PS-568, showing characteristic electronic excitations and optical transitions. 
Here, $m_{0}$ is the mass of an electron in grams and $v_{f}$ is the volume of the 'formula unit' of a PS monomeric unit. For PS with a density of $1.03 \mathrm{~g} \mathrm{~cm}^{-3},[53,66]$ the volume of a styrene formula unit $\left(\mathrm{C}_{8} \mathrm{H}_{8}\right)$ is $166.22 \AA^{3}\left(1 \AA^{3}=0.001 \mathrm{~nm}^{3}\right)$. The $n_{\text {eff-v }}(E)$ of the oscillator strength sum rule for PS is shown in Fig. 11.

\section{Van der Waals-London Dispersion Interactions}

Once the electronic structure of PS has been determined, the full spectral Hamaker constant, which sets the magnitude of the vdW-Ld attraction between two materials separated by an interlayer, can be calculated by the Lifshitz theory. ${ }^{[67,68]}$ The Hamaker coefficient is a function of distance, and incorporates the effects of the retardation of the interaction at larger distances, because of the finite speed of light. For cases where this effect of retardation of the interaction can be neglected, one can calculate the Hamaker constant, which is a simple number and is valid for small distances. In the following, we describe the calculation of a Hamaker constant for a simple three-layer model.

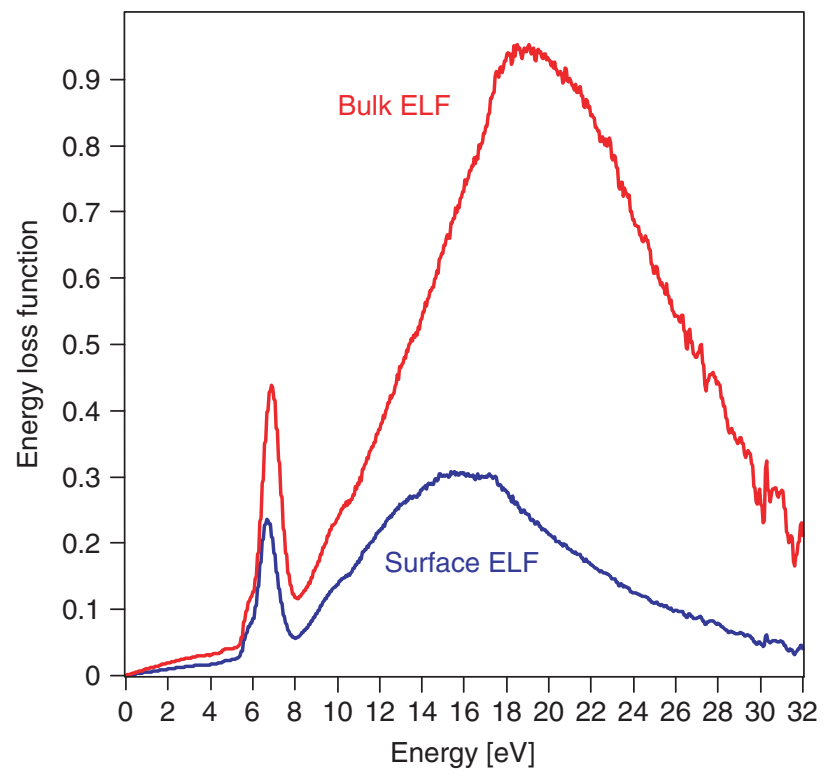

Fig. 10. Bulk electron energy loss function, $-\operatorname{Im}(1 / \varepsilon)$, and surface energy loss function, $-\operatorname{Im}(1 /(\varepsilon+1))$ of polystyrene sample PS-568, showing a lowenergy peak and the bulk and surface plasmon resonance peaks at higher energies.

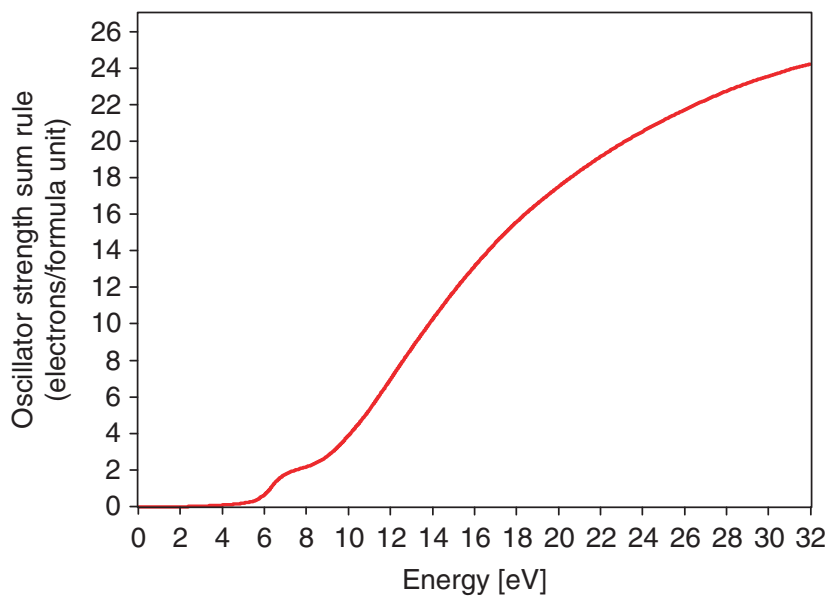

Fig. 11. Oscillator strength sum rule for sample PS-568.
For three layer configurations, the Hamaker constant and coefficient are typically comparable and the role of retardation is small for distances of a few nanometers. In addition, the literature has typically ignored this role of retardation and reports simple Hamaker constants. Beyond simple three-layer configurations, we have also developed methods for more complex Hamaker coefficient calculations that can be used to represent complex multilayer or graded interfaces. ${ }^{[7,8,69]}$ These methods are all included in the Gecko Hamaker program. ${ }^{[70]}$

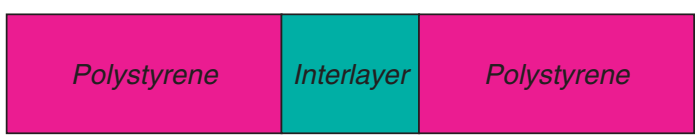

Fig. 12. Configuration of two layers of polystyrene separated by an interlayer film.

\section{Three-Layer Hamaker Constants}

For the case of two semi-infinite halfspaces of material 1 separated from each other by one unique intervening 'interlayer' material 2 of thickness $b$ shown in Fig. 12, in the three-layer (121) configuration, the non-retarded Hamaker coefficient, $A_{121}^{N R}$, can be calculated following Ninham and Parsegian ${ }^{[71]}$ as shown in Eqn 16:

$$
A_{121}^{N R}=-12 \pi b^{2} G_{v d W-L d}(b)
$$

where $G_{v d W-L d}(b)$ is the van der Waals-London dispersion interaction free energy per unit surface area in the non-retarded limit of small interlayer separations. Although retardation effects from the finite velocity of light are small at small separations, ${ }^{[69]}$ they are included in our computations. Mathematical details for the formulation of the van der Waals interactions with incorporated retardation effects are omitted here and published elsewhere. ${ }^{[2,10]} G_{v d W-L d}(b)$ can be obtained from Eqn 17. ${ }^{[6,10,59]}$

$$
G_{v d W-L d}=\frac{\hbar}{4 \pi^{2}} \int_{0}^{\infty} \rho d \rho \int_{0}^{\infty} \ln D_{121}(\xi) d \xi
$$

The secular determinant of electromagnetic field modes $D_{121}(\xi)$ is obtained again in the non-retarded limit from the following (Eqn 18). ${ }^{[6,10,59]}$

$$
D_{121}(\xi)=1-\Delta_{12}^{2}(i \xi) e^{-2 b \rho}
$$

$\Delta_{12}^{2}(i \xi)$ represents the difference of the London dispersion spectra on the two sides of an interface between materials 1 and 2 evaluated at imaginary frequencies, given by Eqn 19 .

$$
\Delta_{12}(i \xi)=\frac{\varepsilon_{1}(i \xi)-\varepsilon_{2}(i \xi)}{\varepsilon_{1}(i \xi)+\varepsilon_{2}(i \xi)}
$$

Note here that the magnetic properties of the layers are considered homogeneous, and thus, irrelevant for evaluation of the layer eigenmodes. The London dispersion spectra $\varepsilon(i \xi)$ are obtained from the imaginary part of the dielectric constant $\varepsilon(E)$ as the Kramers-Kronig transformation shown in Eqn 20. ${ }^{6,72]}$

$$
\varepsilon(i \xi)=1+\frac{2}{\pi} \int_{0}^{\infty} \frac{(E / \hbar) \varepsilon^{\prime \prime}(E / \hbar)}{\left(E / \hbar^{2}\right)+\xi^{2}} d(E / \hbar)
$$

The London dispersion spectrum is a material property and represents the retardation of the oscillators. In this three-layer 
system, the interfacial material shields the attraction of the two PS layers. The Hamaker coefficient is large for a vacuum interlayer and zero if the interfacial material 2 is identical to material 1.

\section{London Dispersion Components of Surface Energy}

Since the Hamaker constant represents the vdW-Ld interaction energy of two materials, it gives the dispersion contribution to surface and interface energies. ${ }^{[6]}$ If dispersion forces are the main contribution to the interface energies, we can also calculate the contact angle. Let us consider an $A_{1 \mathrm{v} 1}^{N R}$ Hamaker constant for a material, which represents the London interaction for two grains of material 1 separated by vacuum (v). Let us also assume for now that this is a non-polar material, such as a polyethylene, in which the surface energy is determined by the dispersion interactions. If we evaluate the Hamaker constant at a value $d_{o}$, which corresponds to an equilibrium separation such as an interatomic bond length or the interchain spacing in the polymer, then we have calculated twice the surface energy of material 1 . Typically the value of $d_{o}$ is taken to be $0.165 \mathrm{~nm} .{ }^{[73]}$ Similarly, if we evaluate the $A_{1 \mathrm{v} 3}^{N R}$ Hamaker constant between two different materials 1 and 3 for an appropriate $d_{o}$ separation, again separated by vacuum, then we have calculated the interface energy for an interface of material 1 and 3. To calculate the surface and interface energies requires the calculation of $A^{N R}$ [liquid | vacuum | liquid] and $A^{N R}$ [solid | vacuum | liquid], then using Eqns 21 and 22, resulting in $\gamma_{l}$ and $\gamma_{s-l}$ :

$$
\begin{aligned}
\gamma_{\text {Mat. } 1} & =-\frac{1}{2} E_{\text {Mat. } 1}=\frac{A_{1 \mathrm{v} 1}}{24 \pi d_{o}^{2}} . \\
\gamma_{\text {Mat.1Mat.3 }} & =-\frac{1}{2} E_{\text {Mat.1Mat.3 }}=\frac{A_{1 \mathrm{v} 3}}{24 \pi d_{o}^{2}} .
\end{aligned}
$$

These equations correspond to the London contribution to the interface energies. In materials classes where Eqns 21 and 22 correspond to the total interface energies, then we can use the Young equation, Eqn 2, to determine the contact angle $\theta$, which in terms of Hamaker constants, and assuming a constant value of $d_{o}$, is given in Eqn 23:

$$
\theta=\arccos \left(\frac{A_{121}}{A_{123}}-1\right)
$$

Polar and Dispersive Contributions to Surface Energy Using the Fowkes Method

Once the contact angles of two fluids with varying polarity (typically one is non-polar such as diiodomethane and one is polar such as water) on a solid surface have been measured, the Fowkes method ${ }^{[14]}$ allows the determination of the polar and dispersive components of the surface free energy. The Fowkes method uses the Young equation (Eqn 2) and the Young-Dupre equation for the work of adhesion (Eqn 3) and produces the simple Eqn 24:

$$
\cos \theta=-1+2 \sqrt{\gamma_{s}^{\text {Disp. }}}\left(\sqrt{\gamma_{l}^{\text {Disp. }}} / \gamma_{l}\right)
$$

where $\gamma_{s}^{\text {Disp. }}$ and $\gamma_{l}^{\text {Disp. }}$ are the dispersive components of the surface free energy of the solid and liquid, respectively, and $\gamma_{l}$ is the total (i.e. dispersive and polar components summed) surface free energy of the liquid. With known properties of the liquid, a simple plot of $\cos \theta$ vs $\sqrt{\gamma_{l}^{\text {Disp. }}} / \gamma_{l}$ should give a straight line with the origin fixed, and provides the dispersive component of the surface free energy of the solid. For convenience, and to allow sampling two or more fluids with known total and dispersive components of the surface free energy, the Fowkes method can be rearranged as shown in Eqn 25. ${ }^{[13]}$

$$
\sqrt{\gamma_{l}^{\text {Disp. }}} \sqrt{\gamma_{s}^{\text {Disp. }}}+\sqrt{\gamma_{l}^{\text {Polar }}} \sqrt{\gamma_{s}^{\text {Polar }}}=\frac{\gamma_{l}(\cos \theta+1)}{2}
$$

\section{Discussion}

We have used two different sources of PS in this study, PS-568 and PS-677, where the first was received as a clear PS sample box commercially prepared by injection moulding and the second was received as pellets that we subsequently compression moulded. The PS-568 has a very high-quality optical surface finish is easily available, and therefore, was superior for the VUV reflectance and contact angle measurements. We compare the UV optical properties from ellipsometry of the two sources of PS to show their similarity.

\section{Optical Properties and Electronic Structure of Polystyrene Index of Refraction}

The index of refraction of PS at the sodium D-line $(589.3 \mathrm{~nm})$ as determined by ellipsometry is 1.580 and 1.590 for PS-568 and PS-677, respectively. These indices compare to values of 1.590 to 1.592 for the D-line index of PS of density $1.06 \mathrm{~g} \mathrm{~cm}^{-3}$. ${ }^{[74]}$ The lower index of the PS-568 PS may because it has a lower reported density. The complex index of refraction, consisting of its real component, the index of refraction, $n$, and its imaginary component, and the extinction coefficients, $\mathrm{k}$, for PS-568 and PS-677 (Fig. 3), are closely comparable both in the energies of the features seen in $n$ and $\mathrm{k}$, and in the amplitude of the measured optical properties. The region of normal index dispersion is also shown, where the index increases with increasing energy as the two absorption features seen at $5.8 \mathrm{eV}$ (shoulder) and $6.3 \mathrm{eV}$ (peak) are approached. However, the doublet peak in the index is shown at lower energies than the corresponding, and KramersKronig dispersion related, features in the extinction coefficient. The region of anomalous dispersion from 6 to $7 \mathrm{eV}$ is shown, where the index decreases with increasing energy, while at energies where the aromatic transitions are strong. This region is followed by normal dispersion seen in Fig. 3 from 7 to $8.55 \mathrm{eV}$. The complex index of refraction over the complete energy range studied shows that there is a second extensive region of anomalous behaviour beyond $10 \mathrm{eV}$ associated with the strong optical absorptions in this region.

\section{Optical Absorption Coefficient}

The optical absorption coefficient in the UV (Fig. 6) shows the close similarity of the two sources of PS, and that the peak value of the optical absorption coefficient at $6.7 \mathrm{eV}$ is approximately $7 \times 10^{5} \mathrm{~cm}^{-1}$. Note that the absorption coefficient is reported as $\log _{e}$, while typically optical absorbance or optical densities are reported as $\log _{10}$. The optical absorption coefficient determined from the full VUV properties (Fig. 7) shows a peak absorption coefficient for the $6.7 \mathrm{eV}$ peak to be in the order of $10^{6} \mathrm{~cm}^{-1}$ base e, and the disagreement between these two results gives a sense of the uncertainty in absorption coefficient values. Many times the energy of the band gap, or highest occupied molecular orbital (HOMO) to lowest unoccupied molecular orbital (LUMO) gap is determined by fitting either direct or indirect models to the absorption coefficient spectra. ${ }^{[75]}$ We have not applied these methods here, but note 
Table 3. Features in interband transitions of polystyrene

\begin{tabular}{|c|c|c|c|c|c|c|c|}
\hline \multirow[t]{2}{*}{ Reference } & \multicolumn{2}{|c|}{$\operatorname{Aromatic}\left(\pi \rightarrow \pi^{*}\right)$} & \multicolumn{2}{|c|}{ Non-bonding $\left(\mathrm{n} \rightarrow \pi^{*}, \mathrm{n} \rightarrow \sigma^{*}\right)$} & \multicolumn{3}{|c|}{ Saturated $\left(\sigma \rightarrow \sigma^{*}\right)$} \\
\hline & $\mathrm{E} 1^{\prime}$ & E1 & $\mathrm{E} 2^{\prime}$ & E2 & E3' & E3 & E4 \\
\hline Rocco et al. ${ }^{[26]}$ & 5.3 & 7.7 & & 10.3 & 13.7 & 17.1 & \\
\hline Styrene monomer & & & & 11.8 & & & \\
\hline This work & $5.8 \mathrm{~s}$ & $6.3 \mathrm{p}^{\mathrm{A}}$ & & $9.9 \mathrm{~s}^{\mathrm{A}}$ & $12 \mathrm{~s}$ & $17.1 \mathrm{~s}^{\mathrm{A}}$ & $21.2 \mathrm{p}^{\mathrm{A}}$ \\
\hline
\end{tabular}

${ }^{\mathrm{A}} \mathrm{S}=$ shoulder, $\mathrm{p}=$ peak

Table 4. Features in bulk and surface energy loss functions of polystyrene

\begin{tabular}{lcccc}
\hline Reference & $\begin{array}{c}\text { E1' energy in } \\
\text { bulk ELF [eV] }\end{array}$ & $\begin{array}{c}\text { E1 energy in } \\
\text { bulk ELF [eV] }\end{array}$ & $\begin{array}{c}\text { Surface plasmon } \\
\text { energy [eV] }\end{array}$ & $\begin{array}{c}\text { Bulk plasmon } \\
\text { energy [eV] }\end{array}$ \\
\hline Ritsko $^{[24]}$ & & 7.0 & & 18.9 \\
Nakai et al. $^{[25]}$ & $5.8 \mathrm{~s}^{\mathrm{A}}$ & 6.7 & 15.5 & 18.9 \\
This work & $6.9 \mathrm{p}^{\mathrm{A}}$ & & & \\
\hline
\end{tabular}

${ }^{A} \mathrm{~s}=$ shoulder, $\mathrm{p}=$ peak

that if the absorption coefficient curve of Fig. 6 were fitted in the range $0-2 \times 10^{5} \mathrm{~cm}^{-1}$, an gap energy of approximately $5.4 \mathrm{eV}$ would be determined, while fits in the absorption coefficient range from 3 to $6 \times 10^{5} \mathrm{~cm}^{-1}$ would produce a gap energy of approximately $5.8 \mathrm{eV}$. This result demonstrates that gap energies can characterize absorption coefficient spectra, but a 'band gap energy' determined from experimental results does not sensibly have a definitive value.

\section{Interband Transition Strength}

The interband transition strength $\left(J_{c v}\right)$ (Fig. 8) is an optical property that most closely corresponds to the joint density of states including the effects of the dipole matrix elements on determining the strength of the transitions between the valence bands to the conduction bands (or the occupied molecular orbitals to the unoccupied molecular orbitals). It is also a complex property with real and imaginary components, and the real part of $J_{c v}$ corresponds to the absorption of photons and the electronic transitions to excited states.

The origins and nature of the interband transitions of PS, visible in $\operatorname{Re}\left[J_{c v}\right]$ up to $20 \mathrm{eV}$, can be understood by assignment of three groups of transitions, $\mathrm{E}_{1}, \mathrm{E}_{2}$, and $\mathrm{E}_{3}$, corresponding to a hierarchy of interband transitions of aromatic $\left(\pi \rightarrow \pi^{*}\right)$, non-bonding $\left(\mathrm{n} \rightarrow \pi^{*}, \mathrm{n} \rightarrow \sigma^{*}\right)$, and saturated $\left(\sigma \rightarrow \sigma^{*}\right)$ orbitals. This hierarchical assignment is comparable to that proposed by Ritsko, ${ }^{[24]}$ and is similar to the assignments we developed for the polysilanes. ${ }^{[20,21]}$ In PS, strong features in the interband transitions arising from the side chain $\pi$ bonding of the aromatic ring consisting of a shoulder at $5.8 \mathrm{eV}\left(\mathrm{E}_{1}^{\prime}\right)$ and a peak at $6.3 \mathrm{eV}$ $\left(\mathrm{E}_{1}\right)$, and from the $\sigma$ bonding of the $\mathrm{C}-\mathrm{C}$ backbone at $12 \mathrm{eV}$ $\left(\mathrm{E}_{3}^{\prime}\right)$ and $17.1 \mathrm{eV}\left(\mathrm{E}_{3}\right)$ (Fig. 9, Table 3). These $\mathrm{E}_{3}$ transitions have the characteristic critical point line shapes associated with one-dimensionally delocalized electron states in the polymer backbone. The assignment of the $\mathrm{E}_{1}$ transitions to excitations of the side chain aromatic ring of PS is also supported by recent work on styrene monomers, ${ }^{[26]}$ with an observed shift of the aromatic ring transitions from $7.7 \mathrm{eV}$ in the monomer to $6.3 \mathrm{eV}$ in the polymer. A small shoulder at $9.9 \mathrm{eV}\left(\mathrm{E}_{2}\right)$ is associated with excitations possibly from either residual monomer or impurities.

\section{Energy Loss Function}

The energy loss functions (surface and bulk, Fig. 10 and Table 4), show a peak in the bulk energy loss function at $6.9 \mathrm{eV}$ corresponding to the $\mathrm{E}_{1}$ transitions and a lower lying shoulder at $5.8 \mathrm{eV}$ corresponding to the $\mathrm{E}_{1}^{\prime}$ transitions. This $\mathrm{E}_{1}$ feature in the energy loss corresponds to the Ritsko ${ }^{[24]}$ and Nakai et al. ${ }^{[25]}$ results, but it is surprising that these prior studies have not reported the bulk and surface plasmon energies of PS, which we find at 18.9 and $15.5 \mathrm{eV}$. The plasmon energies of a material correspond to collective electron oscillations in the material, and are very important for electron energy loss spectroscopy. Typically, it is these energies which are first reported, rather than a small feature seen in the energy loss function.

\section{Oscillator Strength Sum Rule}

The optical sum rules, when applied to quantitative optical properties, permit the direct determination of index of refraction and the oscillator strength. The oscillator strength sum rule (Fig. 11) shows the number of electrons which have undergone transitions as a function of the photon energy, or transition energy. We plotted the number of electrons per formula unit, and for a PS monomeric unit $\left(\mathrm{CH}_{2}-\mathrm{CH}\left(\mathrm{C}_{6} \mathrm{H}_{5}\right)\right.$ or simplified to $\mathrm{C}_{8} \mathrm{H}_{8}$ ), and expect a total of 40 electrons could undergo transitions. These valence electrons consist of four valence electrons per carbon, of which two are C 2 s electrons, and two are C $2 p$ electrons, and one valence electron for each hydrogen atom. In the sum rule, a distinct shoulder below $8 \mathrm{eV}$ arises from the $\mathrm{E}_{1}$ transitions of the side chain aromatic rings of PS, corresponding to 2.5 electrons having undergone transitions by $8.5 \mathrm{eV}$. Our observation of 2.5 electrons involved in the $\mathrm{E}_{1}$ transitions compares to a sum rule value of only 0.3 electrons reported by Nakai et al., ${ }^{[25]}$ which is a large underestimation of the six electrons expected in that work to have undergone transitions by this energy. Over the full VUV data range we observe 24.2 electrons have undergone transitions by $32 \mathrm{eV}$, and underestimate compared to the expected 40 electrons, but this underestimation is typical of the oscillator strength sum rule, since more transitions will appear at larger transition energies. 
Table 5. Full spectral Hamaker constants $A_{123}^{N R}$ for van der Waals-London dispersion interaction of different physical configurations with polystyrene, amorphous $\mathrm{SiO}_{2}$, or water as one component, determined from interband transition strength spectra

The d-line index of PS $=1.596$, water $=1.33, \alpha-\mathrm{SiO}_{2}=1.44$, and $A_{121}=A_{212}$

\begin{tabular}{|c|c|c|c|c|c|}
\hline Physical geometry & Hamaker coeff. $[\mathrm{zJ}]^{\mathrm{A}}$ & Physical geometry & Hamaker coeff. [zJ] & Physical geometry & Hamaker coeff. $[\mathrm{zJ}]$ \\
\hline [PS | vacuum | PS] & 70.9 & {$\left[\mathrm{SiO}_{2} \mid\right.$ vacuum $\left.\mid \mathrm{SiO}_{2}\right]$} & 71.6 & [water | vacuum | water] & 34.2 \\
\hline [PS | water | PS] & 7.71 & {$\left[\mathrm{SiO}_{2} \mid\right.$ water $\left.\mid \mathrm{SiO}_{2}\right]$} & 8.06 & [water | water | water] & 0 \\
\hline$\left[\mathrm{PS}\left|\alpha-\mathrm{SiO}_{2}\right| \mathrm{PS}\right]$ & 1.53 & {$\left[\mathrm{SiO}_{2}\left|\mathrm{SiO}_{2}\right| \mathrm{SiO}_{2}\right]$} & 0 & [water $\left|\mathrm{SiO}_{2}\right|$ water $]$ & 8.04 \\
\hline \multicolumn{6}{|c|}{ Literature results for [PS | water $\mid$ PS] reported by Bos et al. ${ }^{[12]}$} \\
\hline $\begin{array}{l}{[\mathrm{PS} \mid \text { water | PS }]} \\
\text { from contact angles }\end{array}$ & 5 & $\begin{array}{l}\text { [PS | water | PS] from } \\
\text { macroscopic measurements }\end{array}$ & $3.5-5.3$ & & \\
\hline $\begin{array}{l}\text { [PS | water | PS] } \\
\text { from Dagastine et al. }{ }^{[46]}\end{array}$ & 8.90 & $\begin{array}{l}\text { [PS | water | PS }] \text { from } \\
\text { Dagastine et al. }{ }^{[46]} \text { using } \\
\text { Parsegian and Weiss }{ }^{[47]} \text { PS }\end{array}$ & 9.63 & & \\
\hline
\end{tabular}

$\mathrm{A}_{1 \mathrm{zJ}}=10^{-21} \mathrm{~J}$.

Table 6. The van der Waals-London dispersion component of surface free energy and interface free energies of polystyrene, water, and amorphous silica, as determined from full spectral Hamaker constants assuming $d_{o}=0.165 \mathrm{~nm}$

\begin{tabular}{lccc}
\hline vdW-Ld surface free energies & $\gamma_{\text {liq. }}^{\text {Disp. }}\left[\mathrm{mJ} \mathrm{m}^{-2}\right]$ & $\mathrm{vdW}-$ Ld interface free energies & $\gamma_{\text {liq. }}^{\text {Disp. }}\left[\mathrm{mJ} \mathrm{m}^{-2}\right]$ \\
\hline$[\mathrm{PS} \mid$ vacuum $]$ & 34.7 & {$[\mathrm{PS} \mid$ water $]$} & 48.0 \\
{$[$ water | vacuum $]$} & 16.6 & {$\left[\mathrm{PS} \mid \mathrm{SiO}_{2}\right]$} & 69.0 \\
{$\left[\mathrm{SiO}_{2} \mid\right.$ vacuum $]$} & 35.0 & {$\left[\mathrm{SiO}_{2} \mid\right.$ water $]$} & 48.0 \\
\hline
\end{tabular}

\section{Van der Waals-London Interactions for Polystyrene}

The London dispersion interaction arises directly from the material's optical properties and electronic structure. Therefore, now that we have determined the complex optical properties over a wide energy range, we now calculate the vdW-Ld interactions of PS using Lifshitz theory. ${ }^{[4-6,10]}$ Here we report the full spectral, non-retarded Hamaker constants $\left(A_{121}^{N R}\right.$ and $\left.A_{123}^{N R}\right)$ in Table 5 for different physical configurations of PS, vacuum, water, ${ }^{[76]}$ and amorphous silica. ${ }^{[72]}$

Consider a physical configuration for a full spectral, nonretarded Hamaker constant calculation that consists of two materials (numbered 1 and 3) separated by an interlayer film (numbered 2). The materials and interlayer film can be composed of any material. For the effects of retardation to be small, and the nonretarded form of the Hamaker constant to be applicable, the film thickness should be $1-2 \mathrm{~nm}$.

A configuration where the 1 and 3 layers are the same material is the symmetrical 121 case (Fig. 12), which is applicable, for example, to particles of PS in a liquid such as water. For this configuration where the interlayer or intergranular film has different physical properties and electronic structure from the bulk material 1 , it is of interest to compare the magnitude of the Hamaker constant. First consider the Hamaker constants for vacuum interlayers. The [PS | vacuum | PS] Hamaker constant of $70.9 \mathrm{zJ}$ (which is the Hamaker constant that will be used below to determine the dispersive component of the surface free energy) is of comparable magnitude to the $\left[\mathrm{SiO}_{2} \mid\right.$ vacuum $\left.\mid \mathrm{SiO}_{2}\right]$ Hamaker constant of $71.6 \mathrm{zJ}$ (which is the basis of silica colloid chemistry). Thus, in this case, PS and amorphous silica are comparable. Many approximations for Hamaker constants, such as the Tabor-Winterton approximation, are based on the index of refraction of the material. On this basis, the much higher index of refraction of PS would erroneously lead to the conclusion that the $A_{1 \mathrm{v} 1}$ Hamaker constant would be larger for PS than for the lower index of refraction of amorphous silica. ${ }^{[75]}$ Note that the
$A_{1 \mathrm{v} 1}$ for water is much smaller (34.2 zJ) than $A_{1 \mathrm{v} 1}$ for either PS or amorphous silica.

In colloid chemistry, the interlayer material of most interest is water. Here, we use the ultraviolet optical properties of water developed from an oscillator model which fits the electronic structure of water, since experimental VUV measurements of liquids are difficult. ${ }^{[76]}$ The $A_{1 \mathrm{w} 1}$ Hamaker constant for [PS | water $\mid \mathrm{PS}]$ is $7.71 \mathrm{zJ}$, much smaller than the $A_{1 \mathrm{v} 1}$ values, with a decrease in the strength of the vdW-Ld interaction by a factor of approximately 10 . Again this $A_{1 \mathrm{w} 1}$ Hamaker constant is comparable to that of $\left[\mathrm{SiO}_{2} \mid\right.$ water $\left.\mid \mathrm{SiO}_{2}\right]$. The $A_{1 \mathrm{w} 1}$ Hamaker constant for PS we report is larger than that reported by Bos et al., ${ }^{[12]}$ which were determined either from macroscopic measurements as $3.5-5.3 \mathrm{zJ}$, or from contact angle measurements as $5 \mathrm{zJ}$. In addition, the $A_{1 \mathrm{w} 1}$ Hamaker constant reported here is smaller $(7.71 \mathrm{zJ})$ than those reported by Dagastine ${ }^{[45,46]}$ from optical spectra constructed for water and PS using damped oscillator fits of either 8.90 or $9.63 \mathrm{zJ}$. Here we use our prior water optical spectra, ${ }^{[76]}$ also constructed from a damped oscillator fit to experimental data; however, in this range of Hamaker constants, subtle differences in the optical spectra used can change the calculated Hamaker constants.

Use of the Lifshitz theory and measured spectral optical properties may be a more direct path to determine the Hamaker constant. As shown in Table 5, the Hamaker constant is $0 \mathrm{zJ}$ for any configuration in which the interlayer material is the same as the bulk materials, for example [PS | PS | PS]. Thus, the optical contrast is zero and the Hamaker constant becomes zero.

\section{Surface Energy of Polystyrene and its Dispersive Component}

Because of the nature of surface energies and wetting, there have been many excellent discussions of their role in different materials systems and applications. Johnson and Dettre ${ }^{[77]}$ focussed on wetting of polymers by hydrocarbon solvents, a 
situation in which London dominates. Israelachvili ${ }^{[78]}$ discussed the dispersion force contribution to works of adhesion and contact angles. There has been recent discussion of the role of van der Waals forces in the adhesion of gecko foot hairs to surfaces. ${ }^{[79]}$ Zisman $^{[80]}$ and others ${ }^{[81]}$ compare wetting of low- and highenergy solids, and focus on the measurement of the contact angle, since this is a measurement of surface and interface energy.

\section{Determination of Dispersive Component of Surface Energy}

The dispersive component of the surface or interface energy of a material can be calculated from the Hamaker constant by Eqns 21 and 22 under the approximation of an appropriate value of $d_{o}$. Results for PS are shown in Table 6, where the dispersive component of the surface free energy of PS is $34.7 \mathrm{~mJ} \mathrm{~m}^{-2}$. This value is comparable to the dispersive component of the surface free energy of amorphous silica.

\section{Comparison of Dispersive Component of Surface Energy}

We previously calculated the dispersive contribution to the surface free energy of polymers and for PS of the PS-568 type, and reported an energy of $27 \mathrm{~mJ} \mathrm{~m}^{-2}$. ${ }^{[6]}$ From our results, the value has increased to $34.7 \mathrm{~mJ} \mathrm{~m}^{-2}$, which most probably can be attributed to the more accurate Kramers-Kronig analysis methods developed using ellipsometry to determine the low energy wing of the reflectance. We have previously discussed similar analyses based on changes in the calculated optical properties of $\mathrm{Al}_{2} \mathrm{O}_{3},{ }^{[2]}$ and our current understanding is that the dispersive component of the surface free energy is $34.7 \mathrm{~mJ} \mathrm{~m}^{-2}$ for a PS of 250000 molecular weight and density of $1.03 \mathrm{~g} \mathrm{~cm}^{-3}$.

We have used the Fowkes method of contact angle measurements on diiodomethane and water to determine the surface free energy and the dispersive component for the same PS-568 polystyrene that was used for the VUV optical studies. Sessile drop contact angle measurements have an intrinsic measurement uncertainty; for example, there were typically 5-degree differences in measured contact angles from one set of measurements to another, and this variation is seen even for contact angles which are the average of 10 sequential contact angle measurements. As shown in Table 1, the variability in the contact angles from the two datasets leads to changes in the SFE of 1 or $2 \mathrm{~mJ} \mathrm{~m}^{-2}$, and $3 \mathrm{~mJ} \mathrm{~m}^{-2}$ in the dispersive component of the SFE. The contact angle measurements have uncertainties arising from potential contamination of the fluids used, the details of the sessile drop measurements, contamination of the surfaces, and variation across the surfaces studied.

Further uncertainty in determining the dispersive component of the surface free energy using the Fowkes or Zisman methods arises from the uncertainties or disagreements in the literature on the surface free energy and polarity (or the dispersive and polar components of the surface free energy) of the fluids used. In the Fowkes method, we found large variation in the literature values of the polarity of water and diiodomethane, and this knowledge of the fluid's polarity is essential to the accuracy of the Fowkes method. The surface free energies of water and diiodomethane are well established, as shown in Table 2, but the polarity of water is surprisingly uncertain, as Chen and Wakida ${ }^{[38]}$ reported $29.1 \mathrm{~mJ} \mathrm{~m}^{-2}$, while Ström et al. ${ }^{[39]}$ and Bos et al. ${ }^{[12]}$ report $21.8 \mathrm{~mJ} \mathrm{~m}^{-2}$ as the dispersive component of the surface free energy. These uncertainties in the polarity of water also produce variation in the calculated SFE and the polar component of the SFE, but not in the dispersive component of the SFE.
We determine the polarity of PS-568 polystyrene to be either 0.007 or 0.027 using Chen and Wakida ${ }^{[38]}$ and Bos et al. ${ }^{[12]}$ water parameters, respectively. This polarity is lower than that reported in the literature for PS in the Polymer Handbook ${ }^{[36]}$ or by Wu. ${ }^{[41]}$ This result may arise because the PS-568 samples studied here are injection moulded samples, in which either the polar side chain groups of the polymer have retracted from the surface of the sample, or there may be residual mould release agents present on the surface of the samples studied.

This sample-based variability demonstrates another uncertainty introduced into the contact angle measurement determinations of SFE. Another source of variability in the reported SFEs and its components arises from their variation with temperature, molecular weight, and density, and these changes are larger than the measurement uncertainties involved in the Fowkes method with contact angle measurements.

\section{Conclusions}

The interband optical properties of polystyrene (PS) in the vacuum ultraviolet (VUV) region have been investigated using combined spectroscopic ellipsometry and VUV spectroscopy. Over the range $1.5-32 \mathrm{eV}$, the optical properties exhibit electronic transitions we assign to three groupings, $\mathrm{E}_{1}, \mathrm{E}_{2}$, and $\mathrm{E}_{3}$, corresponding to a hierarchy of interband transitions of aromatic $\left(\pi \rightarrow \pi^{*}\right)$, non-bonding $\left(\mathrm{n} \rightarrow \pi^{*}, \mathrm{n} \rightarrow \sigma^{*}\right)$, and saturated $\left(\sigma \rightarrow \sigma^{*}\right)$ orbitals. In PS, strong features in the interband transitions arise from the side chain $\pi$ bonding of the aromatic ring that consist of a shoulder at $5.8 \mathrm{eV}\left(\mathrm{E}_{1}^{\prime}\right)$ and a peak at $6.3 \mathrm{eV}\left(\mathrm{E}_{1}\right)$, and from the $\sigma$ bonding of the $\mathrm{C}-\mathrm{C}$ backbone at $12 \mathrm{eV}\left(\mathrm{E}_{3}^{\prime}\right)$ and $17.1 \mathrm{eV}\left(\mathrm{E}_{3}\right)$. These $\mathrm{E}_{3}$ transitions have the characteristic critical point line shapes associated with one-dimensionally delocalized electron states in the polymer backbone. A small shoulder at $9.9 \mathrm{eV}\left(\mathrm{E}_{2}\right)$ is associated with excitations possibly from residual monomer or impurities. Knowledge of the valence electronic excitations of a material provides the necessary optical properties to calculate the van der Waals-London dispersion interactions using Lifshitz quantum electrodynamics theory and full spectral optical properties. We then determined Hamaker constants and the van der Waals-London dispersion component of the surface free energy for PS. We compared these Lifshitz results to the total surface free energy of PS, its polarity, and its dispersive component of the surface free energy as determined from contact angle measurements with two liquids, and also with literature values. The Lifshitz approach using full spectral Hamaker constants is a more direct determination of the van der Waals-London dispersion component of the surface free energy of PS than other methods.

\section{Acknowledgments}

We are grateful to Dr L. K. Denoyer for software development, M. F. Lemon for VUV spectroscopy assistance, and B. B. French for editing the manuscript.

\section{References}

[1] J. D. van der Waals, Verhandel. Konink. Akad. Weten. Amsterdam 1893, 1, 8 [transl. publ. by J. S. Rowlinson, J. Stat. Phys. 1979, 20, 200].

[2] R. H. French, J. Am. Ceram. Soc. 2000, 83, 2117.

[3] H. C. Hamaker, Physica 1937, 4, 1058. doi:10.1016/S00318914(37)80203-7

[4] E. M. Lifshitz, Sov. Phys. JETP 1956, 2, 73.

[5] I. E. Dzyaloshinskii, E. M. Lifshitz, L. P. Pitaevskii, Adv. Phys. 1961, 10, 165. doi:10.1080/00018736100101281

[6] R. H. French, J. Am. Ceram. Soc. 1990, 73, 477. 
[7] K. van Benthem, G. L. Tan, L. K. Denoyer, R. H. French, M. Rühle, Phys. Rev. Lett. 2004, 93, 227201. doi:10.1103/PHYSREVLETT. 93.227201

[8] K. van Benthem, G. Tan, R. H. French, L. K. Denoyer, R. Podgornik, V. A. Parsegian, Phys. Rev. B 2006, 74, 205110. doi:10.1103/PHYSREVB.74.205110

[9] R. F. Rajter, R. H. French, W. Y. Ching, W. C. Carter, Y. M. Chiang, J. Appl. Phys. 2007, 101, 054303. doi:10.1063/1.2709576

[10] V. A. Parsegian, Van der Waals Forces, A Handbook for Biologists, Chemists, Engineers, and Physicists 2005 (Cambridge University Press: Cambridge).

[11] P. G. de Gennes, Rev. Mod. Phys. 1985, 57, 827. doi:10.1103/ REVMODPHYS.57.827

[12] R. Bos, H. C. van der Mei, H. J. Busscher, FEMS Microbiol. Rev. 1999, 23, 179. doi:10.1016/S0168-6445(99)00004-2

[13] C. Rulison, So You Want to Measure Surface Energy 1999 (Kruss USA: Charlotte, NC).

[14] F. M. Fowkes, Ind. Eng. Chem. 1964, 56, 40. doi:10.1021/ IE50660A008

[15] J. J. Ritsko, L. J. Brillson, R. W. Bigelow, T. J. Fabish, J. Chem. Phys. 1978, 69, 3931. doi:10.1063/1.437131

[16] B. W. Yates, D. M. Shinozaki, A. Kumar, W. J. Meath, J. Polym. Sci. B: Polym. Phys. 1992, 30, 185. doi:10.1002/POLB.1992.090300207

[17] H. R. Philipp, D. G. Legrand, H. S. Cole, Y. S. Liu, Polym. Eng. Sci. 1987, 27, 1148. doi:10.1002/PEN.760271507

[18] S. Hashimoto, K. Seki, N. Sato, H. Inokuchi, J. Chem. Phys. 1982, 76, 163. doi:10.1063/1.442755

[19] H. R. Philipp, H. S. Cole, Y. S. Liu, T. A. Sitnik, Appl. Phys. Lett. 1986, 48, 192. doi:10.1063/1.96940

[20] F. M. Schellenberg, R. L. Byer, R. H. French, R. D. Miller, Phys. Rev. B, Rapid Comm. 1991, 43, 10008.

[21] R. H. French, J. S. Meth, J. R. G. Thorne, R. M. Hochstrasser, R. D. Miller, Synth. Met. 1992, 50, 499. doi:10.1016/03796779(92)90205-W

[22] S. Loughin, R. H. French, L. K. DeNoyer, W.-Y. Ching, Y.-N. Xu, J. Phys. D 1996, 29, 1740. doi:10.1088/0022-3727/29/7/009

[23] W. Y. Ching, Y.-N. Xu, R. H. French, Phys. Rev. B 1996, 54, 13546. doi:10.1103/PHYSREVB.54.13546

[24] J. J. Ritsko, Photon, Electron, and Ion Probes 1981, Ch. 3, pp. 35-44 (American Chemical Society: Columbus, $\mathrm{OH}$ ).

[25] Y. Nakai, K. Matsuda, T. Takagaki, T. Ideta, Optical Properties of Polystyrene and Styrene-MMA Copolymers in the Vacuum Ultraviolet presented at International Conference on Vacuum Ultraviolet Radiation Physics 1971 (Tokyo).

[26] M. L. M. Rocco, G. G. B. De Souza, M. C. A. Lopes, C. A. Lucas, Quim. Nova 1998, 21, 43.

[27] (a) B. Taylor, Phil. Trans. R. Soc. London 1712, 27 [538.c.xx], 131. (b) F. Hauksbee, Phil. Trans. R. Soc. London 1712, 27 [539.c.xiv], 131 [both of these papers are reproduced in the preface of R. Finn, Equilibrium Capillary Surfaces 1986 (Springer: New York, NY)].

[28] T. Young, Phil. Trans. R. Soc. London 1805, 95, 65. doi:10.1098/RSTL. 1805.0005

[29] J. W. Gibbs, Connect. Acad. Trans., 3 1875-1877, 108, 343.

[30] J. W. Gibbs, The Scientific Papers of J. Willard Gibbs: Thermodynamics 1993 (Ox Bow Press: Woodbridge, CT).

[31] J. D. van der Waals, Verhandel. Konink. Akad. Weten. Amsterdam 1893, 1, 8 [transl. publ. by J. S. Rowlinson, J. Stat. Phys. 1979, 20, 200].

[32] J. W. Cahn, J. Chem. Phys. 1977, 66, 3667. doi:10.1063/1.434402

[33] J. W. Cahn, J. E. Hilliard, J. Chem. Phys. 1958, 28, 258. doi: $10.1063 / 1.1744102$

[34] S. Dietrich, Fluid Interfaces: Wetting, Critical Adsorption, van der Waals Tails and the Concept of the Effective Interface Potential, in Phase Transitions in Surface Films 2 (Eds H. Taub, G. Torzo, H. J. Lauter, S. C. Fain, Jr) 1991, pp. 391-423 (Plenum: New York, NY).

[35] Y. Solomentsev, L. R. White, J. Colloid Interface Sci. 1999, 218, 122. doi:10.1006/JCIS.1999.6389

[36] S. Wu, Surface and Interfacial Tensions of Polymers, Oligomers, Plasticizers and Organic Pigments, Polymer Handbook (Eds J. Brandup,
E. H. Immergut, E. A. Grulke, A. Abe, D. R. Bloch) 1999, p. 521 (Wiley-Interscience: New York, NY).

[37] C. J. van Oss, Interfacial Forces in Aqueous Media 2006, p. 29 (CRC Press: New York, NY).

[38] J.-R. Chen, T. Wakida, J. Appl. Polym. Sci. 1997, 63, 1733. doi:10.1002/(SICI)1097-4628(19970328)63:13<1733::AID-APP4> 3.0.CO;2-H

[39] G. Ström, M. Fredriksson, P. Stenius, J. Colloid Interface Sci. 1987, 119, 352. doi:10.1016/0021-9797(87)90280-3

[40] D. G. Legrand, G. L. Gaines, Jr, J. Colloid Interface Sci. 1973, 42, 181. doi:10.1016/0021-9797(73)90022-2

[41] S. Wu, J. Phys. Chem. 1970, 74, 632. doi:10.1021/J100698A026

[42] W. Y. Lau, C. M. Burns, Surf. Sci. 1972, 30, 478. doi:10.1016/00396028(72)90014-3

[43] W. Y. Lau, C. M. Burns, J. Colloid Interface Sci. 1973, 45, 295. doi:10.1016/0021-9797(73)90270-1

[44] W. Y. Lau, C. M. Burns, J. Polym. Sci.: Polym. Phys. Ed. 1974, 12, 431. doi:10.1002/POL.1974.180120215

[45] R. R. Dagastine, D. C. Prieve, L. R. White, J. Colloid Interface Sci. 2000, 231, 351. doi:10.1006/JCIS.2000.7164

[46] R. R. Dagastine, D. C. Prieve, L. R. White, J. Colloid Interface Sci. 2002, 249, 78. doi:10.1006/JCIS.2002.8239

[47] V. A. Parsegian, G. H. Weiss, J. Colloid Interface Sci. 1981, 81, 285. doi:10.1016/0021-9797(81)90325-8

[48] M. N. Bellon-Fontaine, N. Mozes, H. C. Van Der Mei, J. Sjollema, O. Cerf, P. G. Rouxhet, H. J. Busscher, Cell Biophys. 1990, $17,93$.

[49] J.Visser, Ph.D. Thesis: The Adhesion of Colloidal Particles to a Planar Surface in Aqueous Solutions 1973, pp. 1-108 (Council for National Academic Awards: London).

[50] M. L. Bortz, R. H. French, Appl. Spectrosc. 1989, 43, 1498. doi: $10.1366 / 0003702894204092$

[51] D. J. Jones, R. H. French, H. Muellejans, S. Loughin, A. D. Dorneich, P. F. Carcia, J. Mater. Res. 1999, 14, 4337.

[52] www.althor.com (Althor Products: Bethel, CT).

[53] Chevron Phillips Chemical Company: Woodlands, TX.

[54] Woollam Spectroscopic Ellipsometer (J. A. Woollam Co.: Lincoln, NE).

[55] B. Johs, R. H. French, F. D. Kalk, W. A. McGahan, J. A. Woollam, Optic. Interfer. Coat. 1994, 2253, 1098.

[56] Y. N. Xu, W. Y. Ching, R. H. French, Phys. Rev. B 1993, 48, 17695. doi:10.1103/PHYSREVB.48.17695

[57] R. H. French, S. J. Glass, F. S. Ohuchi, Y.-N. Xu, F. Zandiehnadem, W. Y. Ching, Phys. Rev. B 1994, 49, 5133. doi:10.1103/PHYSREVB. 49.5133

[58] R. H. French, D. J. Jones, S. Loughin, J. Am. Ceram. Soc. 1994, 77, 412. doi:10.1111/J.1151-2916.1994.TB07009.X

[59] R. H. French, J. B. Blum, Ceram. Trans. 1990, 7, 111.

[60] K. van Benthem, C. Elsässer, R. H. French, J. Appl. Phys. 2001, 90, 6156. doi:10.1063/1.1415766

[61] R. H. French, Phys. Scr. 1990, 41, 404. doi:10.1088/0031-8949/ 41/4/005

[62] M. L. Bortz, R. H. French, Appl. Phys. Lett. 1989, 55, 1955. doi:10.1063/1.102335

[63] The electronic structure tools (EST) consists of programs for the quantitative analysis of optical, VUV, and EELS spectra. EST was developed under Grams, a PC-based spectroscopy environment; http://www.deconvolution.com (Deconvolution and Entropy Consulting: Ithaca, NY).

[64] F. Wooten, Optical Properties of Solids 1972, p. 49 (Academic: New York, NY).

[65] D. Y. Smith, Dispersion Theory, Sum Rules, and Their Application to the Analysis of Optical Data, in Handbook of Optical Constants of Solids (Ed. E. D. Palik) 1985, pp. 35-68 (Academic: New York, NY).

[66] D. Schrader, Physical Constants of Poly(styrene), in Polymer Handbook (Eds J. Brandup, E. H. Immergut, E. A. Grulke, A. Abe, D. R. Bloch) 1999, p. V-91 (Wiley-Interscience: New York, NY).

[67] E. M. Lifshitz, Sov. Phys. JETP 1956, 2, 73. 
[68] I. E. Dzyaloshinskii, E. M. Lifshitz, L. P. Pitaevskii, Adv. Phys. 1961 10, 165. doi:10.1080/00018736100101281

[69] R. Podgornik, R. H. French, V. A. Parsegian, J. Chem. Phys. 2006, 124, 044709. doi: 10.1063/1.2150825

[70] Gecko Hamaker is an open source, cross platform database application for calculation of complex multilayer Hamaker coefficients, including the effects of retardation, from interband transition strength spectra of materials, available at http://geckoproj.sourceforge.net/, and is licensed under the Gnu Public License (http://www.gnu.org/copyleft/ gpl.html\#SEC1)

[71] B. W. Ninham, V. A. Parsegian, J. Chem. Phys. 1970, 52, 4578. doi:10.1063/1.1673689

[72] G. L. Tan, M. F. Lemon, R. H. French, D. J. Jones, Phys. Rev. B 2005 , 72, 205117. doi:10.1103/PHYSREVB.72.205117

[73] J. N. Israelachvili, Intermolecular and Surface Forces, 2nd edn 1992 (Academic: London).

[74] J. C. Seferis, Refractive Indices of Polymers, in Polymer Handbook (Eds J. Brandup, E. H. Immergut, E. A. Grulke, A. Abe, D. R. Bloch) 1999, p. 521 (Wiley-Interscience: New York, NY).
[75] G. L. Tan, M. F. Lemon, R. H. French, J. Am. Ceram. Soc. 2003, 86 , 1885. doi:10.1111/J.1151-2916.2003.TB03577.X

[76] H. D. Ackler, R. H. French, Y. M. Chiang, J. Colloid Interface Sci 1996, 179, 460. doi:10.1006/JCIS.1996.0238

[77] R. E. Johnson, R. H. Dettre, Wetting of Low-Energy Surfaces, in Wettability, Surfactant Science Series, Vol. 49 (Ed. J. C. Berg) 1993, pp. 1-73 (Marcel Dekker: New York, NY).

[78] J. N. Israelachvili, J. Chem. Soc. Faraday 2 1973, 69, 1729 doi:10.1039/F29736901729

[79] K. Autumn, Y. A. Liang, S. T. Hsieh, W. Zesch, W. P. Chan, T. W. Kenny, R. Fearing, R. J. Full, Nature 2000, 405, 681. doi:10.1038/ 35015073

[80] W. A. Zisman, Adv. Chem. 1964, 43, 1.

[81] R. J. Good, L. A. Girifalco, J. Phys. Chem. 1960, 64, 561. 